This item was submitted to Loughborough's Research Repository by the author.

Items in Figshare are protected by copyright, with all rights reserved, unless otherwise indicated.

\title{
An investigation of manual transmission drive rattle
}

PLEASE CITE THE PUBLISHED VERSION

PUBLISHER

Professional Engineering Publishing / @ IMECHE

VERSION

VoR (Version of Record)

LICENCE

CC BY-NC-ND 4.0

REPOSITORY RECORD

De la Cruz, Miguel, Stephanos Theodossiades, and Homer Rahnejat. 2019. "An Investigation of Manual Transmission Drive Rattle". figshare. https://hdl.handle.net/2134/6515. 
This item was submitted to Loughborough's Institutional Repository (https://dspace.lboro.ac.uk/) by the author and is made available under the following Creative Commons Licence conditions.

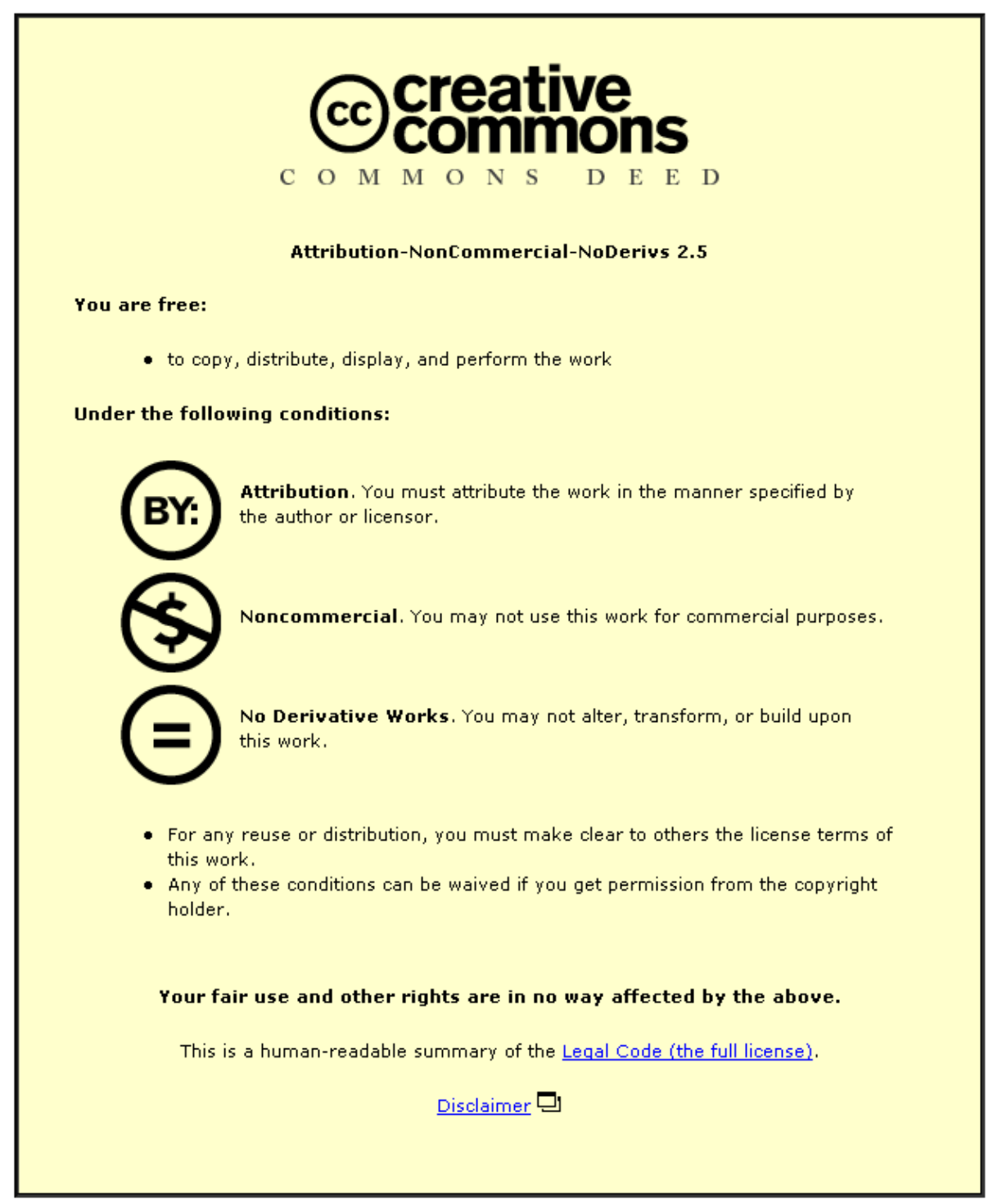

For the full text of this licence, please go to: http://creativecommons.org/licenses/by-nc-nd/2.5/ 


\title{
An investigation of manual transmission drive rattle
}

M De la Cruz, S Theodossiades, and H Rahnejat*

Wolfson School of Mechanical and Manufacturing Engineering, Loughborough University, Loughborough, UK

The manuscript was received on 7 July 2009 and was accepted after revision for publication on 27 August 2009.

DOI: 10.1243/14644193JMBD232

\begin{abstract}
Manual transmission gear rattle is an NVH (noise, vibration, and harshness) concern in the automotive industry. It is induced by repetitive impacts on loose (unselected) gear wheel teeth by their corresponding driving pinions. This phenomenon occurs under various loading conditions and is classified accordingly, including 'idle rattle' when the transmission is in neutral and 'creep and drive rattle' when the transmission is in a gear with a widely open or a partially open throttle. The phenomenon is also present from drive to coast conditions, referred to as overrun rattle. Engine order fluctuations on the input shaft are considered to be the underlying cause for rattle of loose gears. However, the mechanism of transmission of vibration through lubricated contacts is not fundamentally understood. It is surmised that changes in lubricated contact conditions at different bulk oil temperatures may play a key role and, therefore, offer an opportunity to deal with rattle by a root-cause fundamental solution. This means that a detailed multi-physics approach (including dynamics, vibration, and tribology) is needed.

This article provides detailed analytical models of lubricated conjunctions in a multi-body dynamics model of a transaxle seven-speed transmission system under creep rattle conditions. The results show the important role of the regime of lubrication in lightly loaded conjunctions, increasing the propensity to rattle at higher temperatures. It is also revealed that the effect of engine order vibration as an initiating source for rattle becomes significant with reduced hydrodynamic contact stiffness at rising temperatures.
\end{abstract}

Keywords: noise, vibration, and harshness, multi-body dynamics of manual transmissions, creep rattle, lubricated conjunctions, thermo-elastohydrodynamics

\section{INTRODUCTION}

Gear teeth impacts (rattle) are induced by oscillation and the impact of loose (unselected) gears within the confines of their clearances. These oscillations are partly caused by torsional fluctuations, particularly present in diesel engine output torque [1]. The effect of impacting teeth is affected by their contact stiffness and the simultaneous impacts (meshing frequency) at any moment of time. Factors such as transmission error should also be taken into account when dealing with new forcing functions [2]. The oscillations induced in the system are transmitted through the output shaft and support bearings and then onto the transmission case, radiating noise. The geometry of

\footnotetext{
*Corresponding author: Wolfson School of Mechanical and Manufacturing Engineering, University of Loughborough, Loughborough, Leicestershire LE11 3TU, UK.

email:h.rahnejat@lboro.ac.uk
}

the interacting bodies generates a highly non-linear problem [3].

Although it is widely believed not to cause any failure (only Brancati et al. [4], based on a large body of literature reviewed, stated that rattle can cause wear), perception of noise would be regarded as low-quality manufacture and could lead to warranty claims.

When the transmission is considered to run under drive rattle conditions (gear selected with a partially or widely open throttle), unselected gears still mesh due to proximate position of transmission shafts and are, therefore, prone to rattle [2].

Lubricated contact analysis has been previously conducted for the lightly loaded cases under idle rattle conditions [4-6], where the regime of lubrication is considered to be hydrodynamic. The repetitive impacts between teeth are governed by the low stiffness of the lubricant film and not by the Hertzian effective stiffness of mating gear teeth pairs [4]. For drive rattle, the engaged gear pairs experience higher contact loads and operate under the 
elastohydrodynamic regime of lubrication. The lubricant film thickness would normally decrease by an order of magnitude from those under hydrodynamic condition as the lubricant becomes almost incompressible and can also behave as a non-Newtonian fluid under high shear rates. Thus, the lubricant stiffness becomes notoriously higher than the crushing localized stiffness of the adjacent solid bounding surfaces and, consequently, as a first approximation, a Hertzian type analysis is justified. Furthermore, Mehdigoli et al. [7] have shown that the local Hertzian deflection exceeds the oil film surface fluctuations. In drive rattle, the loose gear response is, therefore, also affected by the transmitted vibration from the load bearing engaged gear pair.

The first studies of rattle suggest its attenuation at higher drag torques. A threshold was defined by Seaman et al. [8], where rattle would occur if the inertial torque of a gear at a given acceleration exceeds its resistive drag torque. This led to the idea that an increase in drag torque can be considered as a source of palliation. However, this approach can lead to higher fuel consumption, also requiring a higher engine idling speed. Other palliative methods follow the same principle (i.e. increasing the drag torque thereby avoiding tooth separations). Among these, axial pre-loading of synchronizers and shafts [9], the use of backlash eliminators [10], or even the use of magnetic fields around gear teeth [11] can be mentioned. All these techniques again have the repercussion of increased fuel consumption, as well as an additional shifting effort and increased frictional losses at higher transmission operating temperatures.

Clutch pre-dampers [12] and dual-mass flywheels (DMF) are the palliative trends in modern vehicles. DMFs are tuned for the major engine order contribution (second engine order for a four cylinder four stroke engine), and have proved to be useful in counteracting rattle to a certain extent. However, they have no effect upon meshing frequencies (inherent in the rattle spectrum of vibration) and can only work on a narrow band of frequencies. Furthermore, they represent a significant additional cost.

The work presented in this article attempts to model and understand the lubricated conjunctions present in gear teeth pair contacts. This is then integrated with the dynamics of the system to create a model of an entire seven-speed transmission (reverse plus six speeds). The aim is to establish some of the main root causes of drive rattle.

\section{DYNAMIC MODEL OF TRANSMISSION}

The layout of the transmission investigated is shown in Fig. 1. Appropriate ranges for the geometrical and inertial properties of all gear sets are listed in Table 1. This is a front wheel drive six-speed transaxle gear box. It comprises an input shaft and two output shafts.

The input shaft carries known engine order oscillations. Engine torsional vibration is measured and its spectral representation is provided as an input, superimposed on the steady-state rotational velocity of the transmission input shaft. For the four-stroke four-cylinder in-line engine, the engine order vibration contributions appear at all the multiples of engine speed, with the most significant being at the second engine order and all its multiples up to the tenth engine order [1].

In the purely torsional transmission shafts model described here, only the dynamics of the gear wheels

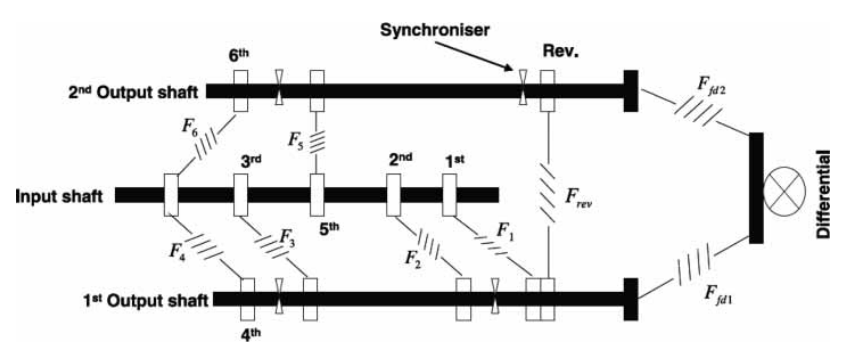

Fig. 1 The transmission system layout

Table 1 Geometrical and inertial properties of all gear sets

\begin{tabular}{|c|c|c|c|c|c|c|c|}
\hline Parameter & $\begin{array}{l}\text { First } \\
\text { gear } \\
\text { wheel }\end{array}$ & $\begin{array}{l}\text { Second } \\
\text { gear } \\
\text { wheel }\end{array}$ & $\begin{array}{l}\text { Third } \\
\text { gear } \\
\text { wheel }\end{array}$ & $\begin{array}{l}\text { Fourth } \\
\text { gear } \\
\text { wheel }\end{array}$ & $\begin{array}{l}\text { Fifth } \\
\text { gear } \\
\text { wheel }\end{array}$ & $\begin{array}{l}\text { Sixth } \\
\text { gear } \\
\text { wheel }\end{array}$ & $\begin{array}{l}\text { Reverse } \\
\text { wheel }\end{array}$ \\
\hline Inertia $\left(\mathrm{kg} \mathrm{m}^{2}\right)$ & $\begin{array}{r}0.0040- \\
0.0043\end{array}$ & $\begin{array}{l}0.0020-0.0023+ \\
0.010+0.02 \text { (second } \\
\text { output shaft) }\end{array}$ & $\begin{array}{r}0.0010- \\
0.0013\end{array}$ & $\begin{array}{r}0.00060- \\
0.00063\end{array}$ & $\begin{array}{r}0.00045- \\
0.00048\end{array}$ & $\begin{array}{r}0.00035- \\
0.00038\end{array}$ & $\begin{array}{r}0.0030- \\
0.0033\end{array}$ \\
\hline Base radius (mm) & $55-60$ & $50-55$ & $40-45$ & $35-40$ & $30-35$ & $30-35$ & $55-60$ \\
\hline Pitch radius (mm) & $60-65$ & $55-60$ & $45-50$ & $35-40$ & $35-40$ & $30-35$ & $55-60$ \\
\hline Gear module (mm) & $2.8-3.1$ & $2.2-2.5$ & $2.1-2.4$ & $2.0-2.3$ & $1.9-2.2$ & $2.0-2.3$ & $3.2-3.5$ \\
\hline Face width (mm) & $17-20$ & $17-20$ & $17-20$ & $17-20$ & $15-18$ & $17-20$ & $17-20$ \\
\hline Helix angle $\left(^{\circ}\right)$ & $25-27$ & $31-33$ & $31-33$ & $31-33$ & $31-33$ & $31-33$ & $19-21$ \\
\hline $\begin{array}{l}\text { Normal pressure } \\
\text { angle }\left(^{\circ}\right)\end{array}$ & $19-21$ & $18-20$ & $18-20$ & $16-18$ & $16-18$ & $16-18$ & $18-20$ \\
\hline
\end{tabular}


need to be modelled (seven degrees of freedom, inclusive of a reverse gear wheel). The main emphasis in this work has been given to the interactions between the lubricated conjunctions that promote rattle. Therefore, transverse and axial motions of the transmission shafts have been considered to be negligible compared to the torsional fluctuations. The condition being investigated is that of transmission drive rattle, when the gear box is engaged in a second gear (loaded pair). Thus, the other gears are loose (unselected, a condition referred to as unloaded). At any time for a given gear pair $i$, a number of teeth $j$ (for loose pairs) or $k$ (for the second gear engaged pair) are in mesh. It should be noted that the current model considers the transmission already engaged in the second gear. The gear shifting process itself does not affect rattle and thus it is not included here. The equations of motion are thus obtained as follows.

For the engaged second speed pinion-wheel pair

$$
\begin{aligned}
\left(I_{2}+I_{\mathrm{os}}\right) \ddot{\varphi}_{2}= & \sum_{k=1, n^{\prime}} W_{2, k} R_{\mathrm{bw} 2}-\sum_{i=1,3,4,7} \sum_{j=1, n} F_{i, j} r_{x i, j} \\
& -\sum_{k=1, n^{\prime}} F_{2, k} r_{x 2, k}-T_{D 2}
\end{aligned}
$$

and for the loose unselected pinion-wheel pairs $i \in 3-6$

$$
I_{i} \ddot{\varphi}_{i}=\sum_{j=1, n^{\prime}} W_{i, j} R_{\mathrm{bw} i}-\sum_{j=1, n^{\prime}} F_{i, j} r_{x i, j}-F_{\mathrm{p} i} R_{\mathrm{brg} i}
$$

The first loose gear wheel and the reverse pinion are mounted together on the first output shaft; thus their combined inertia acts against the first gear pinion, mounted on the transmission input shaft

$$
\begin{aligned}
\left(I_{1}+I_{\mathrm{PR}}\right) \ddot{\varphi}_{1}= & \sum_{j=1, n^{\prime}} W_{1, j} R_{\mathrm{bw} 1}-\sum_{k=1, m^{\prime}} W_{7, k} R_{\mathrm{bw} 7} \\
& -\sum_{j=1, n^{\prime}} F_{1, j} r_{x 1, j}-\sum_{k=1, m^{\prime}} F_{7, k} r_{x 7, k}-F_{p 1} R_{\mathrm{brg} 1}
\end{aligned}
$$

The loose reverse gear wheel is on the second transmission output shaft, which meshes with its reverse pinion counterpart

$$
I_{7} \ddot{\varphi}_{7}=\sum_{k=1, m^{\prime}} W_{7, k} R_{\mathrm{bw} 7}-\sum_{k=1, m^{\prime}} F_{7, k} r_{x 7, k}-F_{p 7} R_{\mathrm{brg} 7}
$$

The right-hand side of the equations provide the driving torques due to the impact forces $W_{i}, i \in 1 \rightarrow$ 7 (the seventh pair refers to the reverse gear) and the resistive friction torques. Note that, at any time, a number of teeth are in contact for any meshing loaded or loose pair, thus the summations indicated over the counters $j$ or $k$. In the case of the engaged pair (second gear), the resistive torque is provided by the flank friction of teeth pairs in mesh and the drive train resistance $T_{\mathrm{D}}$. In the case of the loose gears, there is an additional drag torque due to the conjunctions between the loose wheels' inner surfaces (wheel bore) and their contiguous supporting shafts. The driving and resisting torques need to be determined for the solution of equations of motion. Unlike many of the hitherto reported models, these conjunctions are all lubricated and a detailed analysis is required. Clearly, the equation set alters if rattle condition with any other engaged pair is considered.

\section{TEETH PAIR CONJUNCTIONS}

\subsection{Contact geometry}

The contact surfaces of any mating pair of teeth can be described by a pair of principal radii (in the $x z$ and $y z$ planes as shown in Fig. 2). The contact of teeth pairs may be represented instantaneously as an ellipsoidal solid with two equivalent radii of contact in these planes against a semi-infinite elastic half-space. In the $x z$ plane (Fig. 2(a)), the equivalent radius is (see Table 1 for geometrical data)

$$
r_{x}=\frac{r_{\mathrm{p}} r_{\mathrm{w}}}{r_{\mathrm{p}}+r_{\mathrm{w}}}
$$

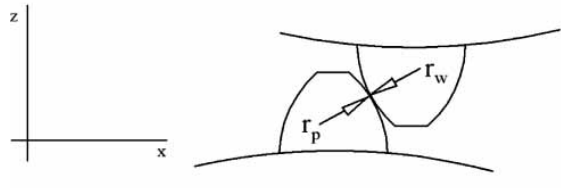

(a)

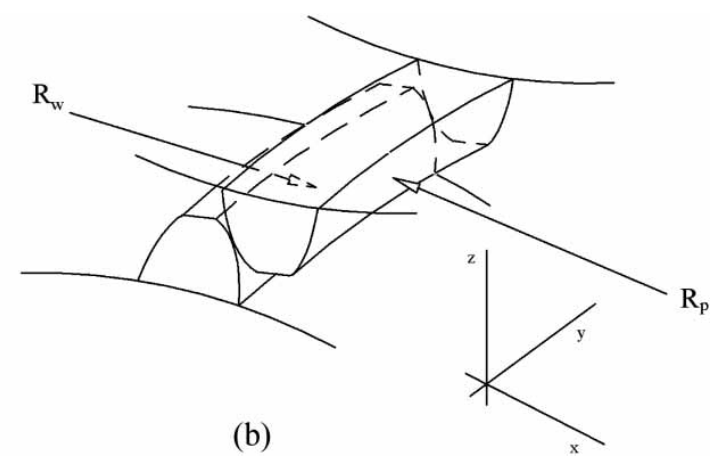

(b)

Fig. 2 Principal radii of bodies in contact 
Note that

$$
\left.\begin{array}{c}
r_{\mathrm{p}}=\sqrt{\left(R_{\mathrm{bp}}^{2}+\rho_{\mathrm{p}}^{2}\right)} \\
r_{\mathrm{w}}=\sqrt{\left(R_{\mathrm{bw}}^{2}+\rho_{\mathrm{w}}^{2}\right)}
\end{array}\right\}
$$

and

$$
\left.\begin{array}{l}
\rho_{\mathrm{w}}=\frac{\sqrt{R_{\mathrm{ow}}^{2}-R_{\mathrm{bw}}^{2}}-\varphi_{\mathrm{p}} R_{\mathrm{bp}}}{\cos \beta} \\
\rho_{\mathrm{p}}=\frac{c_{\mathrm{c}} \sin \alpha_{\mathrm{t}}}{\cos \beta}-\rho_{\mathrm{w}}
\end{array}\right\}
$$

For the $y z$ plane (Fig. 2(b)), a partially conforming contact exists, in which the radius of the wheel is considered as negative due to its concavity; thus

$$
r_{y}=\frac{R_{\mathrm{w}} R_{\mathrm{p}}}{R_{\mathrm{p}}-R_{\mathrm{w}}}
$$

\subsection{Hydrodynamic conjunctions of loose gear pair teeth}

The contact footprint is usually elliptical with ellipticity ratio $[\mathbf{1 3}]$

$$
\frac{a}{b} \approx\left(\frac{r_{y}}{r_{x}}\right)^{2 / 3}
$$

where $a=l / 2$ is the major semi-half-width of the elastostatic contact ellipse, $l$ the length of the contact, and $b$ the minor semi-half-width of the footprint along which the lubricant is entrained into the contact. For the transmission investigated, however, $r_{y}>>r_{x}$; thus an elastic line contact may be assumed as a first approximation and the contact width may be obtained as

$$
b=\left[\frac{4 W r_{x}}{\pi l E^{*}}\right]^{1 / 2}
$$

The hydrodynamic contact/impact load (see Fig. 3) is, therefore, obtained as [14]

$$
W=\frac{2 b u \eta r_{x}}{h}-\frac{3 \pi b \eta}{\sqrt{2}}\left(\frac{r_{x}}{h}\right)^{3 / 2} \frac{\partial h}{\partial t}
$$

where the first term on the right-hand side is due to pure entraining motion of the lubricant, while the second term corresponds to rigid hydrodynamic squeeze film action. The film thickness is obtained as [5]

$$
h=\left\{\begin{array}{rr}
C-\frac{R_{\mathrm{bpi}} \varphi_{\mathrm{p} i}-R_{\mathrm{bw} i} \varphi_{i}}{\cos \alpha_{n} \cos \beta}, & R_{\mathrm{bp} i} \theta_{\mathrm{p} i}>R_{\mathrm{bw} i} \theta_{i} \\
C+\frac{R_{\mathrm{bp} i} \varphi_{\mathrm{p} i}-R_{\mathrm{bw} i} \varphi_{i}}{\cos \alpha_{n} \cos \beta}, & R_{\mathrm{bp} i} \theta_{\mathrm{p} i}<R_{\mathrm{bw} i} \theta_{i} \\
i \in 1 \rightarrow 7 \notin 2
\end{array}\right.
$$

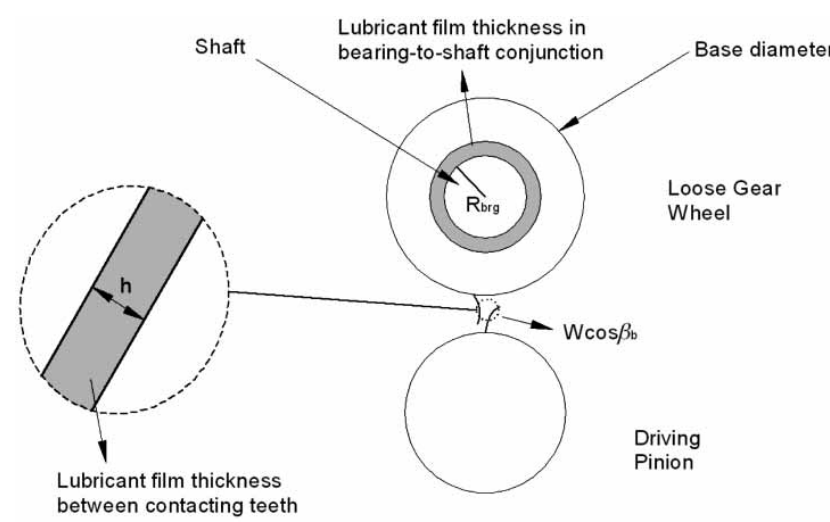

Fig. 3 Hydrodynamic conjunctions in loose gear pairs

The speed of entraining motion and the sliding speeds are obtained as [5]

$$
u=\frac{v_{\mathrm{p}}+v_{\mathrm{w}}}{2}, \quad \Delta u=v_{\mathrm{p}}-v_{\mathrm{w}}
$$

where

$$
\begin{aligned}
& v_{\mathrm{p}}=v_{\text {pitch }, \mathrm{p}}\left(\sin \alpha_{\mathrm{t}}+\frac{l_{\mathrm{p}}}{r_{\mathrm{pp}}}\right) \cos \beta \\
& v_{\mathrm{w}}=v_{\text {pitch,w }}\left(\sin \alpha_{\mathrm{t}}-\frac{l_{\mathrm{p}}}{r_{\mathrm{pw}}}\right) \cos \beta
\end{aligned}
$$

with the kinematic constraint: $v_{\text {pitch,p }}=v_{\text {pitch,w }}$ and $l_{\mathrm{p}}=$ $r_{\mathrm{pw}} \sin \alpha_{\mathrm{t}}-\rho_{\mathrm{w}}$ (see Fig. 4) and the pitch velocities are given as: $v_{\text {pitch,p }}=r_{\mathrm{p}} \dot{\varphi}_{\mathrm{p}}, v_{\text {pitch,w }}=r_{\mathrm{w}} \dot{\varphi}_{\mathrm{w}}$.

The squeeze film velocity $\partial h / \partial t<0$ for approaching surfaces. When the bodies are separating, the squeeze film does not act; thus $\partial h / \partial t=0$ in equation (9). For the first-order approximation, $\partial h / \partial t=h_{k}-h_{k-1} / \Delta t$, where $k$ is the time step identifier and $\Delta t$ is the integration time step of the order of few microseconds.

Flank friction in the hydrodynamic conjunctions of loose gear pair teeth follows the same modelling

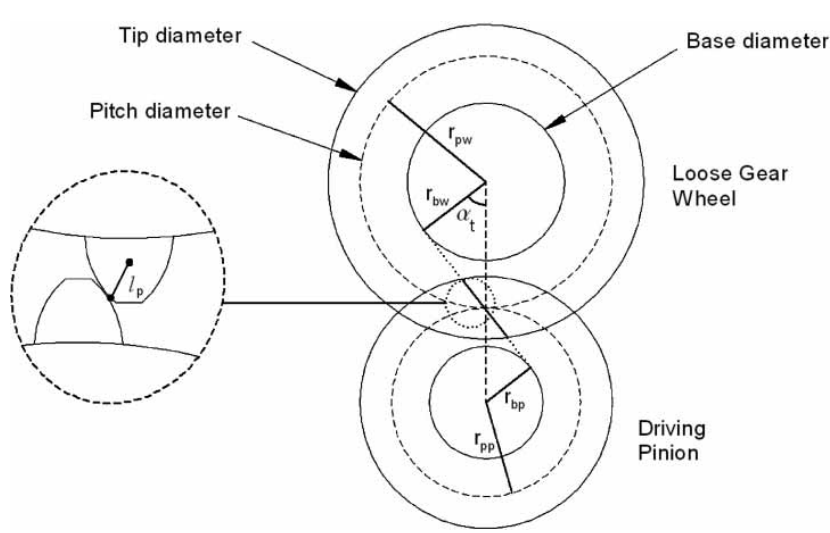

Fig. 4 Meshing cycle geometry of individual teeth pairs in contact 
approach as in reference [15]

$$
F_{\mathrm{fw}}= \begin{cases}\frac{l \pi \eta \Delta u}{\sqrt{2 h}} \sqrt{r_{x}}, & \Delta u \geqslant 0 \\ \frac{-l \pi \eta \Delta u}{\sqrt{2 h}} \sqrt{r_{x}}, & \Delta u<0\end{cases}
$$

The loose gear wheels, when impacted upon, rotate relative to their supporting shaft. These are often mounted on a needle bearing, mounted onto the shaft. The conjunction between the bore of wheels and the outside radius of bearing outer race may be assumed to act as a journal bearing having no eccentricity. One may reasonably assume that the resistive friction of viscous nature is due to the small clearance in the presence of a lubricant film. This is the essence of Petrov friction $[13]$

$$
F_{\mathrm{P}}=\frac{2 \pi \eta u_{\mathrm{brg}} R_{\mathrm{brg}} l_{\mathrm{brg}}}{c}
$$

where the speed of lubricant entrainment is given as

$$
u_{\mathrm{brg}}=\frac{1}{2}\left(R_{\mathrm{brg}} \dot{\varphi}_{\mathrm{w}}+\frac{1}{2 \pi} r_{\mathrm{os}} \dot{\varphi}_{\mathrm{os}}\right)
$$

\subsection{Elastohydrodynamic conjunctions of the selected loaded gear pair teeth}

The selected loaded gear pair is usually subjected to the elastohydrodynamic regime of lubrication. A lubricant film may be assumed with thickness $h_{0}$, which is the result of localized deformation of the contiguous surfaces. The thickness of the film depends on the speed of entraining motion, geometry of the contact, and lubricant viscosity, and is rather insensitive to the applied contact load. Many extrapolated oil film thickness formulae exist that provide the relationship between the film thickness and the aforementioned parameters. These are based on numerical analysis of contacts and subsequent regression analysis of the results in terms of key governing parameters. On the other hand, an initial formula was derived by Grubin [16] based on the assumption of an inlet shape to a conjunction that is subject to Hertzian pressure distribution. The edge of the film is subject to a pressure of $p=1 / \alpha$. Solving the Reynolds pressure gradient in one dimension, Grubin found that

$$
\frac{h_{\mathrm{o}}}{r_{x}}=2.076\left(\frac{\alpha \eta u}{r_{x}}\right)^{8 / 11}\left(\frac{E^{*} l r_{x}}{W}\right)^{1 / 11}
$$

where the reduced elastic modulus is

$$
E^{*}=\frac{E}{1-v^{2}}
$$

All the parameters are found as stated above, except for load per teeth pair contact under loaded conditions (here for the second gear). The contact load is obtained from the principle of conservation of energy from a Hertzian totally elastic impact. This embodies the assumption that the lubricant film in its incompressible state (as under elastohydrodynamic conditions) has negligible damping, which is found to be the case by both Mehdigoli et al. [7] and Dareing and Johnson [17]. Thus, according to Teodorescu et al. [18]

$$
\delta=\left(\frac{2\left\{\ln [(2 l / b)+(1 / 2)] m v_{\mathrm{p}}^{2}\right\}}{\pi L E^{*}}\right)^{1 / 2}
$$

and from Gohar and Rahnejat [13]

$$
W \approx\left\{\frac{\pi l E^{*}}{2[\ln ((2 l / b)+(1 / 2))]}\right\} \delta
$$

where $m$ is the equivalent mass of an ellipsoidal solid of principal radii of curvature $r_{x}$ and $r_{y}$, determined in section 3.1.

Under loaded conditions the lubricant film thickness can be much thinner than that in the case of contacting/impacting teeth pairs of loose gears. Therefore, a mixed regime of lubrication is quite likely at times during their meshing cycles. To ascertain the regime of lubrication, shear stress is obtained in each mating teeth pair contact at every step of analysis $\Delta t$ as: $\tau=\eta \Delta u / h_{0}$. This value is compared with the limiting Eyring shear stress $\tau_{0}$ [19]. If $\tau<\tau_{0}$, then flank friction is calculated as $F_{\mathrm{v}}=\tau A_{\mathrm{e}}$, where $A_{\mathrm{e}}$ is the real contact area, rather than the apparent contact area, indicated by Hertzian theory. With thin elastohydrodynamic films, there is a significant chance of asperity interactions. Therefore, flank friction in loaded pairs is due to a combination of boundary (asperity interactions) and viscous friction. Hence, the total friction is obtained as

$$
F=F_{\mathrm{b}}+F_{\mathrm{v}}
$$

Note that this analysis is confined to the teeth pair of the second gear, which is selected in the present study of the transmission drive rattle.

To determine the value of $F$ for each loaded conjunction, it is necessary to obtain the contact area of asperity pairs. The approach used is that of Greenwood and Tripp [20]

$$
A_{\mathrm{e}}=\pi^{2}(\zeta \kappa \sigma)^{2} A F_{2} \lambda
$$

and the load share of asperities is

$$
W_{\mathrm{e}}=\frac{8 \sqrt{2}}{15} \pi(\zeta \kappa \sigma)^{2} \sqrt{\frac{\sigma}{\kappa}} E^{*} A F_{5 / 2} \lambda
$$

The variables $F_{2}$ and $F_{5 / 2}$ are statistical functions introduced to match the assumed Gaussian distribution of asperities considered [20]. Balakrishnan et al. [21] 


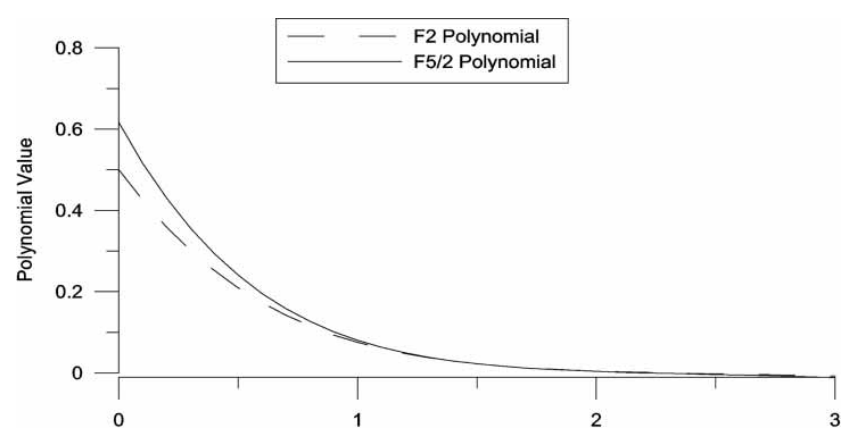

Fig. 5 Fifth-order polynomial fit for $F_{2}$ and $F_{5 / 2}$

propose a fifth-order polynomial fit to describe these functions (see Fig. 5). $\lambda$ is the oil film parameter, first defined by Stribeck [22] as $\lambda=h / \sigma$.

The thin boundary films are considered to act in a non-Newtonian manner, with the limiting Eyring shear stress, $\tau_{0}$. Thus, the boundary friction contribution is given as

$$
F_{\mathrm{b}}=\tau_{\mathrm{o}} A_{\mathrm{e}}+\xi W_{\mathrm{e}}
$$

The Eyring shear stress of the transmission fluid used is $4.5 \mathrm{MPa}$. $\xi$ represents the pressure coefficient of the boundary shear strength for direct asperity interactions, approximated to 0.17 [23].

The viscous friction contribution arises due to the shearing of the lubricant film between the two contacting surfaces where a coherent lubricant film is formed. As already mentioned, for a shear stress below the limiting Eyring value, the viscous friction is considered to follow a Newtonian behaviour. Above this limiting value a non-Newtonian behaviour is expected. In this case, the shear stress depends on further rheological properties. Therefore

$$
\tau= \begin{cases}\frac{\Delta u \eta}{h}, & \frac{\Delta u \eta}{h} \leqslant \tau_{\mathrm{o}} \\ \tau_{\mathrm{o}}+\gamma p^{*}, & \frac{\Delta u \eta}{h}>\tau_{\mathrm{o}}\end{cases}
$$

where

$$
p^{*}=\frac{W-W_{\mathrm{e}}}{A_{\mathrm{e}}}
$$

and $\gamma$ is the slope of the oil film limiting shear stresspressure relationship.

Again, only the actual contact area is needed to be taken into account, not the Hertzian contact area $A_{\mathrm{a}}=$ $2 b l=4\left(W l r_{x} / \pi E^{*}\right)$; thus $F_{\mathrm{v}}=\tau A=\tau\left(A_{\mathrm{a}}-A_{\mathrm{e}}\right)$.

\section{THERMAL EFFECTS}

\subsection{Conjunctions of loose gears}

The analysis described above yields contact and friction forces under isothermal conditions. This has been the approach in nearly all of the transmission rattle literature, except for adjustment of lubricant viscosity due to temperature on a what-if scenario basis, e.g. Tangasawi et al. [5] and Brancati et al. [4]. However, it is understood that lubricant viscosity is significantly affected by temperature and plays a very important role in the rattle phenomenon [24]. Accurate formulation of frictional contributions gives the opportunity to determine the lubricant temperature in the various conjunctions: those of loaded gear teeth, loose gear teeth pairs, and in the loose wheels-to-supporting shafts conjunctions. An analytical solution to the rather complex energy equation involves an order of magnitude analysis of the heat flow due to the various contributing mechanisms as highlighted by Gohar and Rahnejat [13]. They noted that for thicker hydrodynamic films at modest pressures, the mechanism of heat generation is by viscous shear of the film. Heat removal (cooling) is also dominated by convection (heat carried away by the lubricant). Thus, for loose gear pairs and for Petrov friction zones, the energy equation simplifies to

$$
\eta\left(\frac{\partial v}{\partial z^{\prime}}\right)^{2}=\rho \nu C_{\mathrm{p}}\left(\frac{\partial \theta}{\partial x^{\prime}}\right)
$$

To solve equation (22), a linear temperature distribution is assumed along the contact width in the direction of entraining motion as $\partial \theta / \partial x^{\prime}=\Delta \theta / 2 b$. Integrating equation (22) yields the following equation

$$
\frac{2 \eta \Delta u^{2} b}{h}=\frac{\rho C_{\mathrm{p}} \Delta u h \Delta \theta}{4}
$$

from which the rise in temperature in transit through a contact width is obtained as

$$
\Delta \theta=\frac{8 \eta \Delta u b}{h^{2} \rho C_{\mathrm{p}}}
$$

If one assumes that all the heat is taken away by the lubricant through convection and the inlet temperature (oil climbing onto the loose teeth pair conjunctions or that of oil splash) be that of the bulk lubricant in the sump, then $\theta_{0}=\theta_{\text {inlet }}+\Delta \theta$, where $\theta_{0}$ is the average temperature of the lubricant in the contact.

For the loose wheel-to-the supporting shaft bearing conjunction, assuming convection cooling only, for relatively thick hydrodynamic films, one can employ the procedure developed for journal bearings by Gohar and Rahnejat [13] and Cameron [25] to obtain the temperature rise as

$$
\Delta \theta=\left(\frac{2 K_{\mathrm{l}} W_{\mathrm{brg}}}{\rho C_{\mathrm{p}} R_{\mathrm{brg}} l_{\mathrm{brg}}}\right)\left(\frac{\mu^{*}}{Q_{\mathrm{s}}^{*}}\right)
$$


where

$$
\mu^{*}=\frac{\pi \eta u l_{\mathrm{brg}}}{W_{\mathrm{brg}}}\left(\frac{R_{\mathrm{brg}}}{c}\right)^{2} \text { and } Q_{\mathrm{s}}^{*}=\frac{Q_{\mathrm{s}}}{\pi N R_{\mathrm{brg}} l_{\mathrm{brg}} c}=2 \varepsilon
$$

and the coefficient $K_{1}$ indicates that not all the frictional power is lost through convection.

\subsection{Loaded teeth-pair conjunctions}

For thin elastohydrodynamic films, one may assume that heat generated is mainly due to viscous shear heating of the lubricant. This assumption ignores compressive heating due to the pressure gradient, as well as any heating effect due to direct asperity interactions. Inclusion of these influences precludes an analytic solution. Gohar and Rahnejat [13] show that viscous shear heating is the main contributory factor. Furthermore, they show that, for quite thin films, most of the heat is conducted through the bounding solid surfaces. Taking their approach, the following relationship is obtained for temperature rise in loaded conjunction of gear teeth pairs (in this case for the engaged second gear)

$$
\Delta \theta=\frac{2 \eta \Delta u^{2}}{k_{\mathrm{t}}}
$$

This assumes a parabolic temperature distribution across the film.

\subsection{Lubricant viscosity}

The rise in temperature in each conjunction, $\Delta \theta$, causes a corresponding drop in the lubricant viscosity and thus reduces its load-carrying capacity. At the same time, the lubricant viscosity and its load-carrying capacity may be enhanced by increased pressures when the film thickness is reduced. Therefore, both the piezo-viscous (pressure dependency) and thixotropic (shear/thermal dependency) behaviour of the lubricant must be taken into account to obtain realistic values for transmission fluid viscosity in the various conjunctions. For the lightly loaded conjunctions of loose gear pairs, low hydrodynamic pressures do not induce piezo-viscous behaviour. However, the same is not true of the elastohydrodynamic conjunctions of load bearing meshing teeth pairs. The viscosity of the lubricant is determined using the Houpert [26] expression

$$
\eta=\eta_{\mathrm{o}} \mathrm{e}^{\alpha^{*} p}
$$

where $p$ is taken as the mean pressure as

$$
p_{\mathrm{m}}=\left(\frac{\pi W E^{*}}{2 r_{x}}\right)^{1 / 2}
$$

and

$$
\begin{aligned}
\alpha^{*}= & \frac{1}{p}\left[\ln \left(\eta_{\mathrm{o}}\right)+9.67\right]\left\{\left(\frac{\Theta-138}{\Theta_{\mathrm{o}}-138}\right)^{-S_{\mathrm{o}}}\right. \\
& \left.\times\left[\left(1+\frac{p_{\mathrm{m}}}{1.98 \times 10^{8}}\right)^{Z}-1\right]\right\}
\end{aligned}
$$

Also

$$
\begin{aligned}
Z & =\frac{\alpha_{0}}{5.1 \times 10^{-9}\left[\ln \left(\eta_{\mathrm{o}}\right)+9.67\right]} \quad \text { and } \\
S_{\mathrm{o}} & =\frac{\beta_{\mathrm{o}}\left(\Theta_{\mathrm{o}}-138\right)}{\ln \left(\eta_{\mathrm{o}}\right)+9.67}
\end{aligned}
$$

where the bulk oil temperature is

$$
\begin{aligned}
& \Theta_{0}=\theta_{\text {inlet }}+273, \quad \Delta \Theta=\Delta \theta+273 \text {, } \\
& \text { thus: } \Theta=\Theta_{0}+\Delta \Theta
\end{aligned}
$$

\section{RESULTS AND DISCUSSION}

Simulation is conducted at the engine speed of $800 \mathrm{r} / \mathrm{min}$, with the transmission engaged in the second gear. This condition pertains to a particularly noted drive rattle at partial loading, referred to as creep rattle. Tables 2 and 3 list the material and lubricant characteristics introduced in the numerical simulation.

The transmission input shaft, on which all the pinion gears are mounted, is subject to engine order vibrations, superimposed upon the nominal speed of $800 \mathrm{r} / \mathrm{min}$. This signal is measured from the vehicle in situ and is an input to the transmission model. In other words, the motion of the transmission input shaft and all the pinion gears is considered to be kinematic. The spectrum of vibration of this signal is shown in Fig. 6(a). Note that the spectrum is dominated by the engine order multiples, particularly the second engine order $2 \omega$ for the four-cylinder four-stroke in-line diesel engine.

Table 2 Lubricant properties

\begin{tabular}{ll}
\hline Lubricant & $75 \mathrm{~W}-90 \mathrm{BO}$ \\
\hline Dynamic viscosity at $20^{\circ} \mathrm{C}$ & $0.0115 \mathrm{~Pa} \mathrm{~s}$ \\
Density $(\rho)$ & $1500 \mathrm{~kg} / \mathrm{m}^{3}$ \\
Pressure-viscosity coefficient $(\alpha)$ & $0.12 \mathrm{GPa}^{-1}$ \\
Temperature-viscosity coefficient $\left(\beta_{\mathrm{o}}\right)$ & $0.04 \mathrm{~K}^{-1}$ \\
Specific heat capacity $\left(C_{\mathrm{p}}\right)$ & $2.2 \mathrm{~J} / \mathrm{kg} \mathrm{K}$ \\
Thermal conductivity $\left(k_{\mathrm{t}}\right)$ & $0.145 \mathrm{~W} / \mathrm{m} \mathrm{K}$
\end{tabular}

Table 3 Material parameters

\begin{tabular}{ll}
\hline Composite surface roughness $(\sigma)$ & $0.57 \mu \mathrm{m}$ \\
Greenwood parameter $(\zeta \kappa \sigma)$ & 0.055 \\
Modulus of elasticity $(E)$ & $209 \mathrm{GPa}$ \\
Poisson's ratio $(v)$ & 0.33 \\
\hline
\end{tabular}




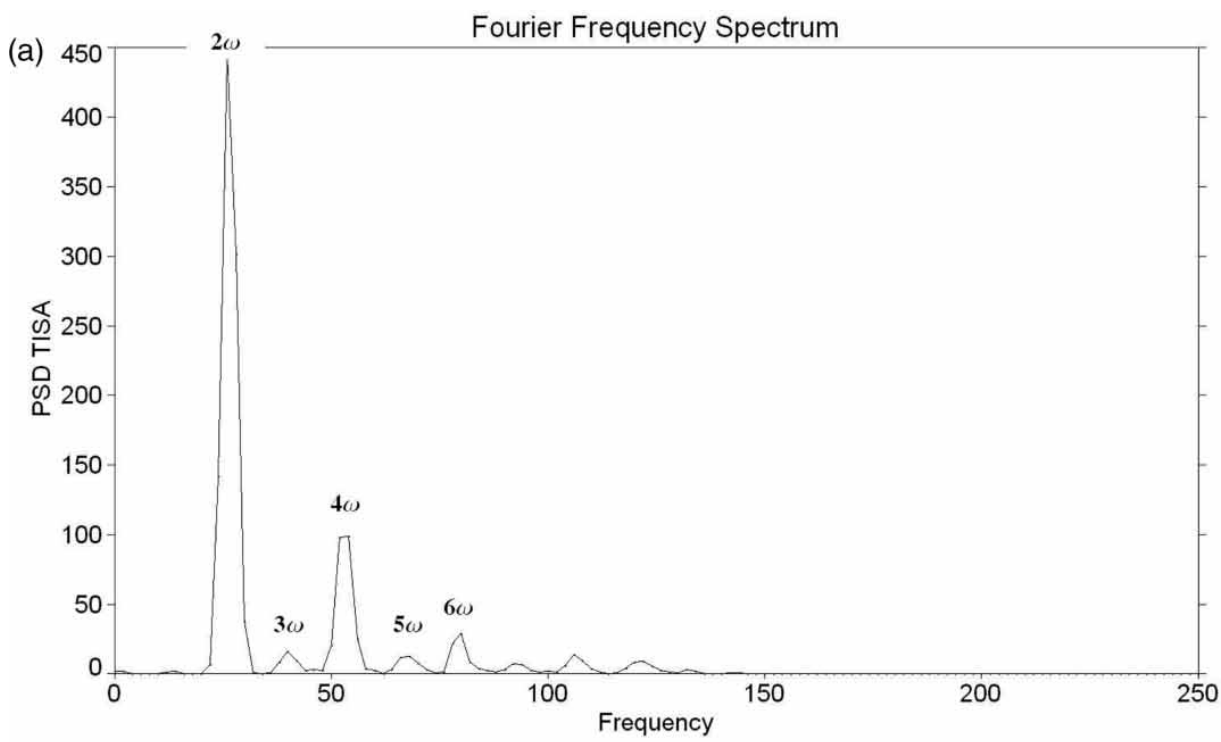

(b)

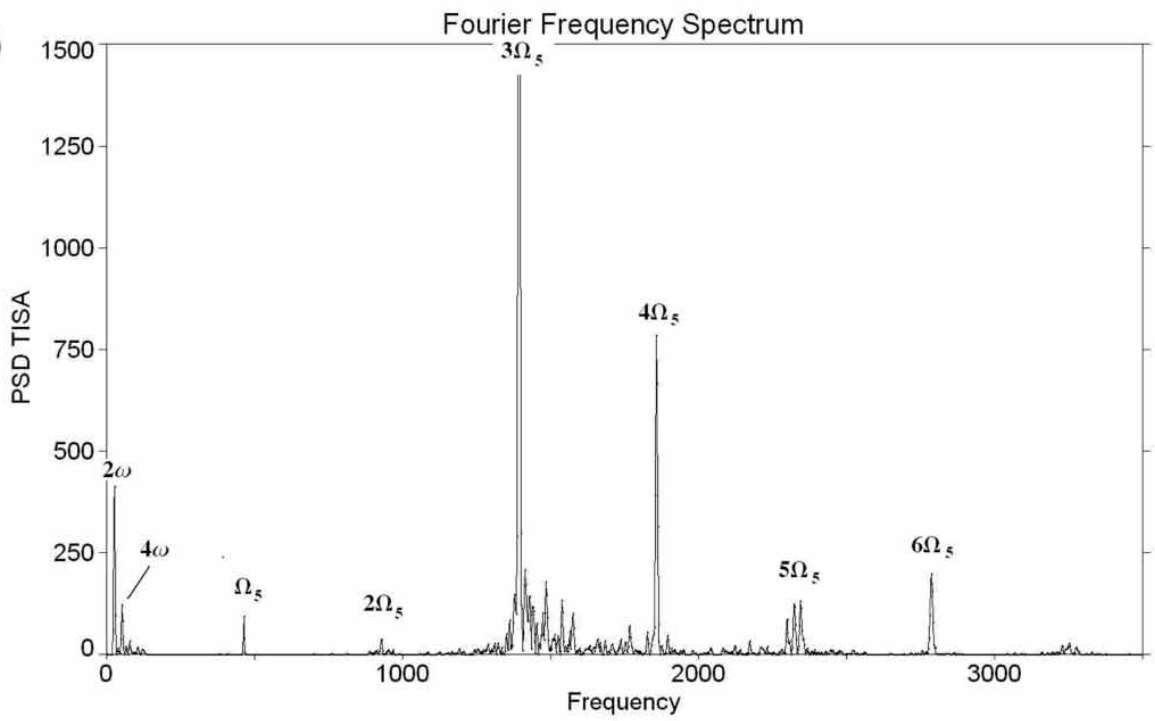

(c)

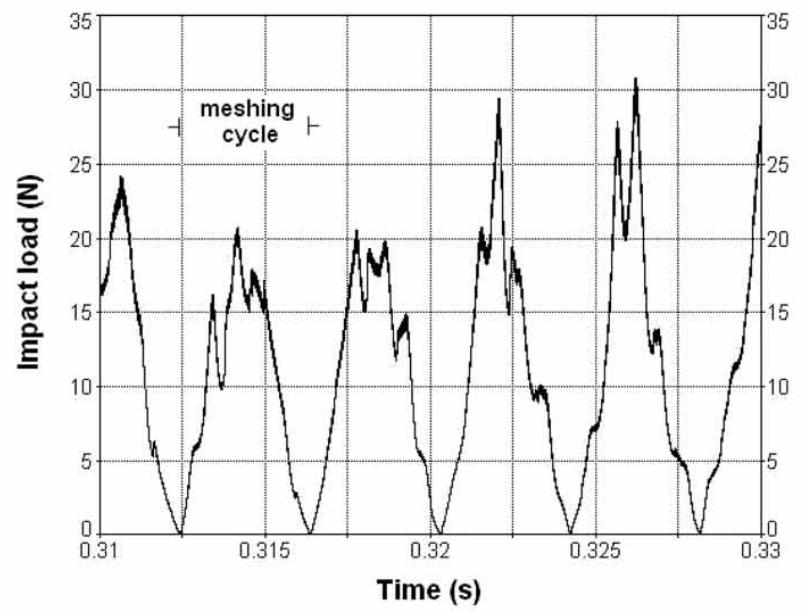

Fig. 6 (a) Input shaft spectrum of rotational acceleration, (b) spectrum of the fifth gear acceleration (fifth loose gear, $\theta_{\text {inlet }}=20^{\circ} \mathrm{C}, C=10 \mu \mathrm{m}$ ), (c) impact force variation in meshing cycles (fifth loose gear, $\theta_{\text {inlet }}=20^{\circ} \mathrm{C}, C=10 \mu \mathrm{m}$ ) 

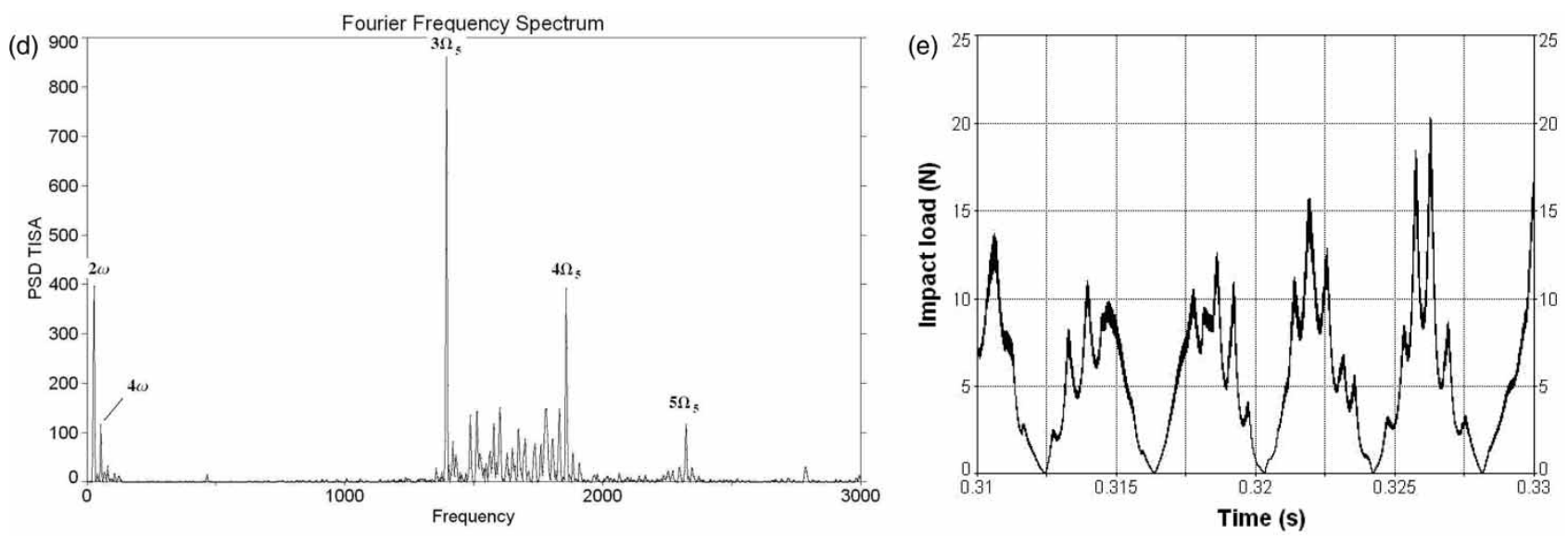

Fig. 6 (continued) (d) spectrum of fifth gear acceleration (fifth loose gear, $\theta_{\text {inlet }}=60^{\circ} \mathrm{C}$, $C=10 \mu \mathrm{m}$ ), and (e) impact force variation in meshing cycles (fifth loose gear, $\theta_{\text {inlet }}=60^{\circ} \mathrm{C}$, $C=10 \mu \mathrm{m})$

Equations of motion (1) to (4) are solved with Newmark's step-by-step linear acceleration method. All the other equations in the previous sections ultimately provide the conjunctional forces at each time step, taking into account contact kinematics, generated pressures, and heat generation.

Figure 6(b) shows the fifth loose wheel's spectrum of rotational acceleration at the bulk oil temperature of $20^{\circ} \mathrm{C}$, with the clearance between it and the retaining shaft being $10 \mu \mathrm{m}$. The lower band of contributions in the spectrum corresponds to the engine order vibrations, and the next band of frequencies are the first meshing frequency $\left(\Omega_{5}=464 \mathrm{~Hz}\right)$ and its harmonics. The very high contribution of the third harmonics indicates that at least three impacts take place during a meshing cycle (see Fig. 6(c)). This is not always repetitive and in fact other harmonics of meshing frequency can also occur (e.g. two, four, or even five peaks may be observed). The substantial contribution at the third meshing frequency implies the way in which impact energy is transferred into kinetic energy of the rigid body in motion.

Figure $6(\mathrm{~d})$ corresponds to the same bearing clearance, but with an increased bulk oil temperature of $60^{\circ} \mathrm{C}$. The contribution at the third harmonics of the meshing frequency is now reduced and a band of frequencies exist in the interval bounded by $3 \Omega_{5}$ and $4 \Omega_{5}$. The orderly meshing of pinion-loose wheel teeth (in the case of $20^{\circ} \mathrm{C}$ ) is clearly interrupted by a more erratic behaviour of the impact force during meshing cycles (see Fig. 6(e)). These contributions are in fact engine order harmonics that vary with the harmonics of meshing frequency. Repetitive squeeze and separation of lubricated conjunctions occur due to reduced lubricant film load-carrying capacity at the higher temperature of $60^{\circ} \mathrm{C}$. There is also clearly a decreased influence of the meshing frequency orders on the loose wheel torsional fluctuations, and since the clearance in the bearing zone is kept constant (in the analysis), the increased temperature (lower viscosity) also points to decreased drag. This implies that the residual impact energy in the form of the aforementioned erratic motions may emanate as airborne noise. More analysis would be required, with the inclusion of hydrodynamics-induced noise, to verify this supposition. However, findings of previous research and industrial measurements all point to the propensity to rattle at higher bulk oil temperatures, which indirectly verifies the supposition made here. Note that the driving hydrodynamic force is with the drive side of the pinion teeth. In extreme cases the separation effect would constitute double-sided impacts as the loaded conjunction switches between the drive and coast sides of the pinion teeth. This condition is likely to occur at even higher bulk oil temperatures and deserves to be the subject of further work.

So far, the results for one of the loose gears under hydrodynamic conditions have been presented. The other loose wheels also demonstrate the same trend with greater or lesser propensity to rattle, depending on their inertial properties. It has been suggested that only the loose gears produce rattle [27]. However, their responses are affected by the interactions of the engaged pair through the transmission shaft. Figure 7 (a) shows the spectrum of vibration of the meshing engaged pair. The relatively small amplitudes of vibration at the meshing frequency and its harmonics indicate that at higher contact loads the oscillations of gears are reduced, when compared with the loose wheels. These higher forces are generated by the lubricated contacts under the elastohydrodynamic regime of lubrication, where the incompressibility of the lubricant mitigates the continual squeeze and separation effect, which is noted in the case of loose gear pairs and is in line with the findings of Rahnejat and Gohar [28] in the case of ball bearings, where in the unloaded zone a greater squeeze effect is noted under hydrodynamic regime of lubrication. 
(a)

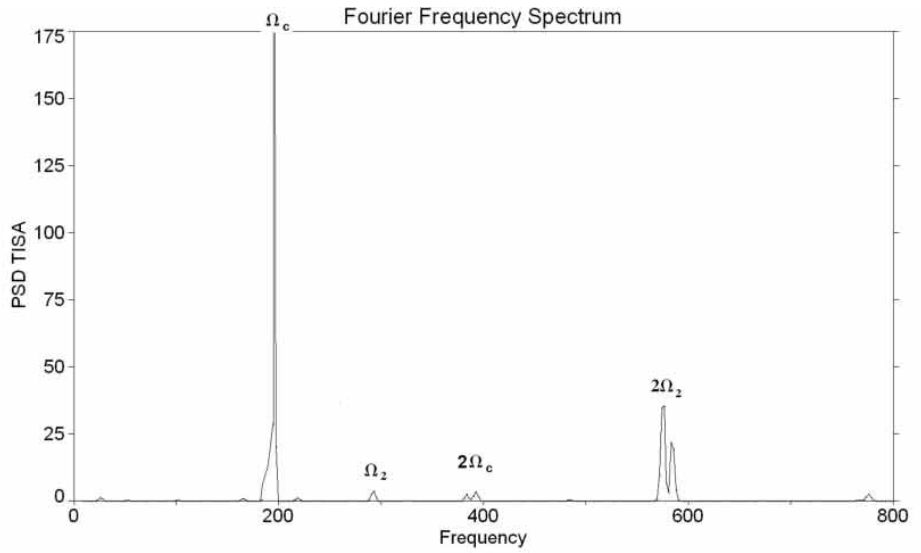

(b)
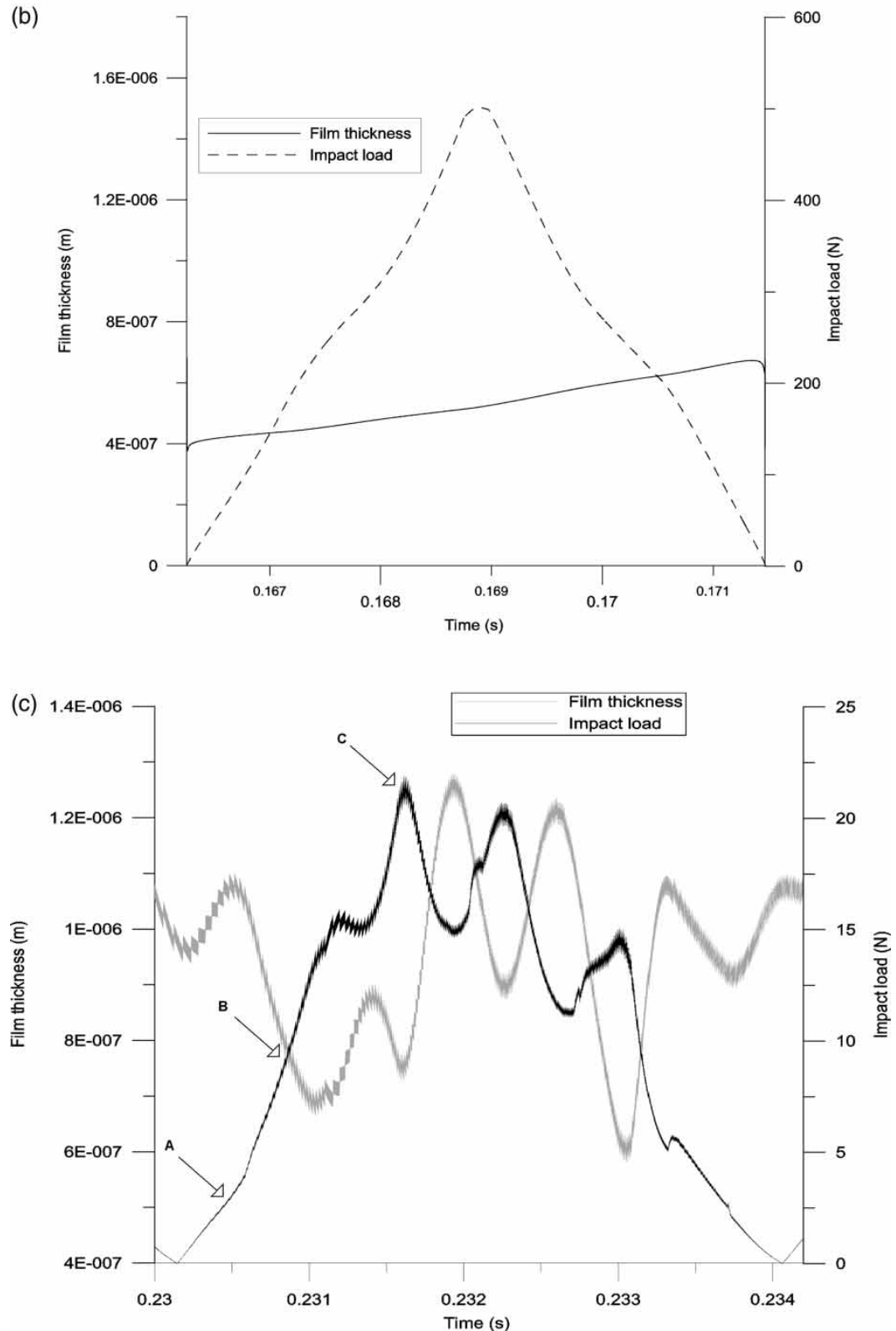

Fig. 7 (a) Spectrum of vibration of the impact force in a typical teeth pair of the loaded gear pair during one cycle of meshing, (b) load and film thickness variations in a teeth pair conjunction during a meshing cycle, (c) minimum film thickness and contact load relationship (fifth loose gear, $\theta_{\text {inlet }}=20^{\circ} \mathrm{C}, C=10 \mu \mathrm{m}$ ) 

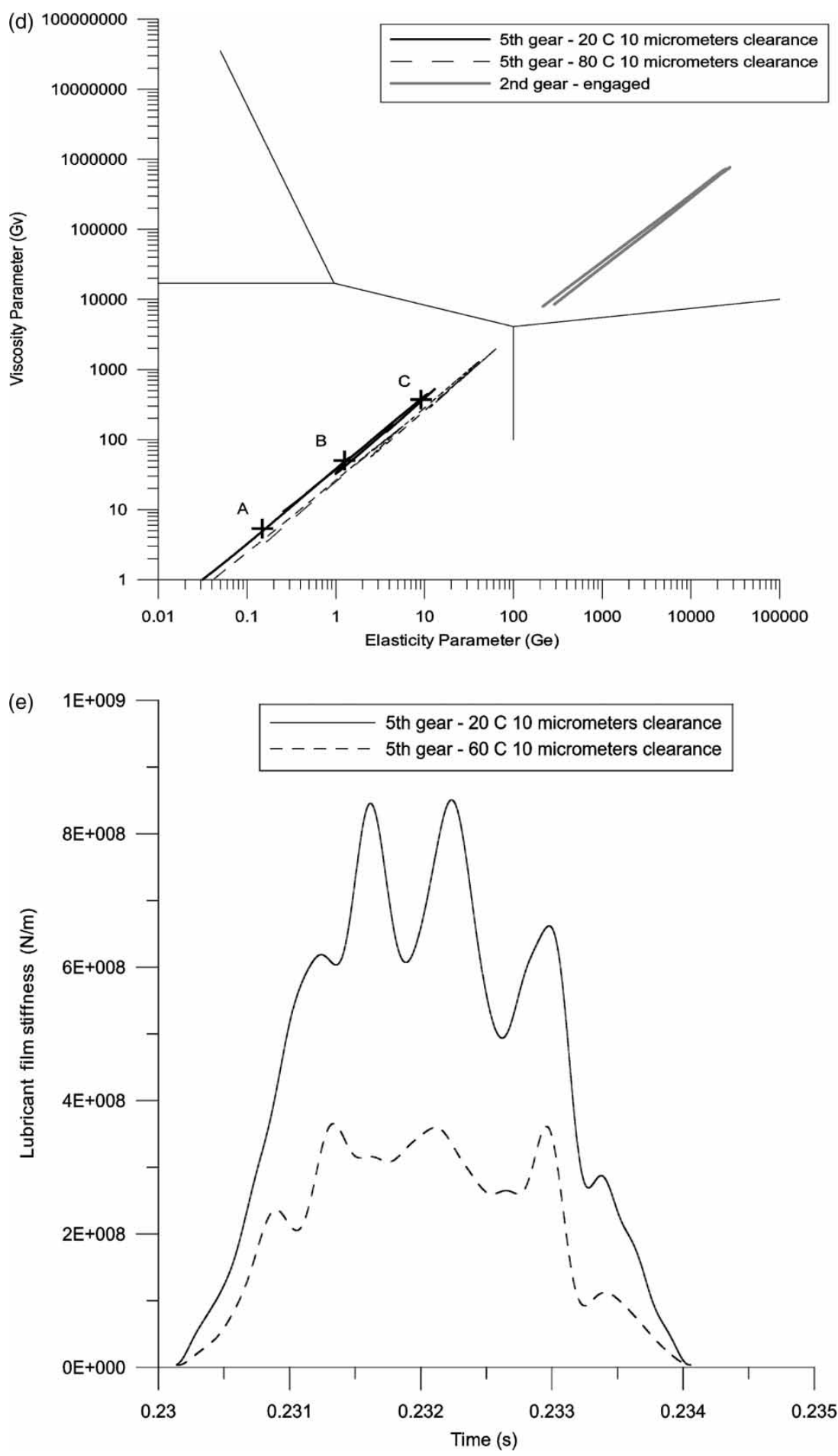

Fig. 7 (continued) (d) Greenwood chart for various contact conditions, and (e) lubricant film stiffness $(\partial W / \partial h)$ variation along the meshing cycle of the fifth loose wheel

There is an additional significant contribution to the spectrum, termed here as the contact frequency, $\Omega_{\mathrm{c}}$. This is the transitional event due to the lubricated contact compliance as pairs of teeth come into contact, slide and roll, and depart. This contribution may be regarded as the main driving force, causing rigid body motion. It would clearly be affected with the introduction of any transmission error or changes in transmission speed or gear teeth geometry.

The aforementioned contact frequency is affected by the stiffness of the elastohydrodynamic lubrication (EHL) film in the form $\partial W / \partial h$ (see equation (14)). It is considered as a transitional frequency, because it alters with speed of entraining motion, lubricant viscosity (thus temperature, etc.). It is also more complex 


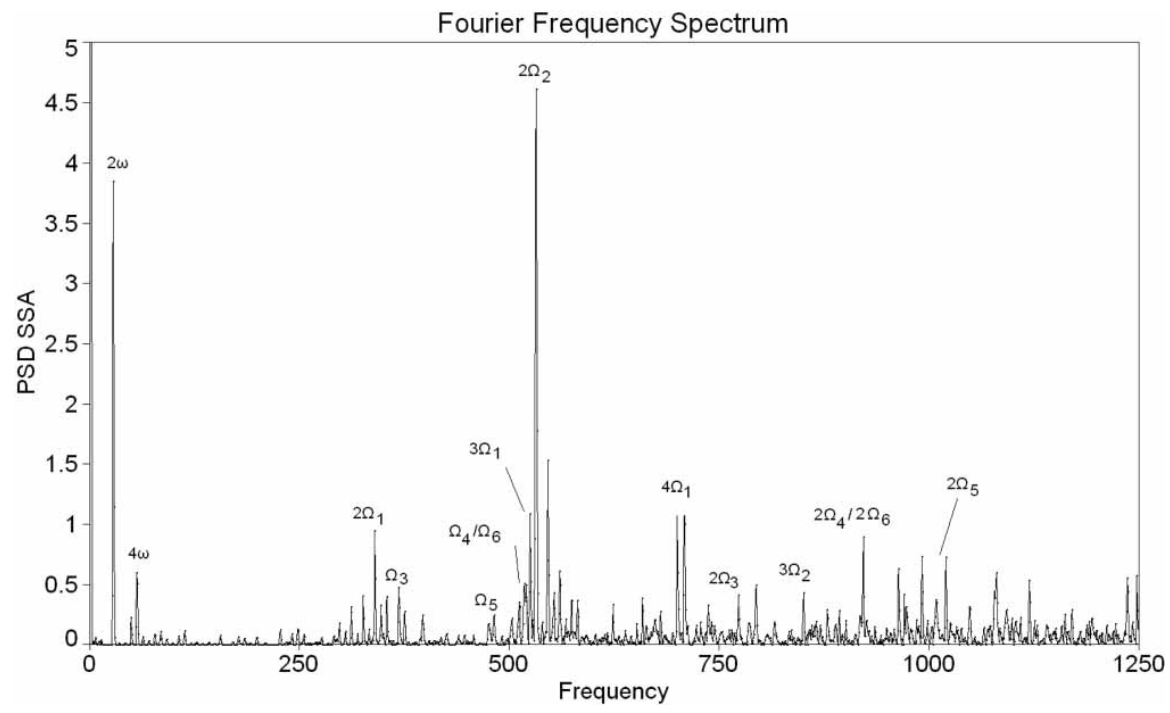

Fig. 8 FFT of accelerometer response at the second output shaft location

than simply using equation (14), because the regime of lubrication is typically mixed as asperity load bearing contribution also plays a part. In fact, under EHL conditions, the film thickness is rather insensitive to load, as can be seen in Fig. 7(b). This is typical of loaded teeth pair contacts under EHL or mixed regime of lubrication. With significant variation in load share of a teeth pair during one meshing cycle, film thickness is hardly altered (Fig. 7(b)). On the contrary, in hydrodynamic lightly loaded contacts of loose gear pairs, there are significant changes in contact stiffness $\partial W / \partial h$, with the inverse relationship between load and film thickness (see equation (9) and Fig. 7(c)).

Figure 7 (c) shows the minimum oil film thickness and impact load on the fifth loose gear. Unlike the variation in Fig. 7(b), the profound changes in $\partial W / \partial h$ are noted. The reciprocal relationship between load and film thickness is more evident at times. Point $A$ in the figure shows a lightly loaded rigid hydrodynamic condition with the film thickness decreasing sharply as the load increases. This is corroborated by the Greenwood chart (Fig. 7(d)). Points B and C, however, do not show this tendency as clearly as point A. They both share a similar film thickness value, but the load is doubled at point $\mathrm{C}$. The conditions are more complex as squeeze film effect and temperature variation cause viscosity changes, as well as contact geometry. However, with thinner films a march towards EHL conditions is quite clear in Fig. 7(d), where the elastic parameter, $G_{\mathrm{e}}=W^{* 8 / 3} / U^{* 2}$, and the viscosity parameter, $G_{\mathrm{v}}=G^{*} W^{* 3} / U^{* 2}$. The key point is that the contact stiffness as a function of $\partial W / \partial h$ alters continually during the meshing cycle (Fig. 7(e)). This leads to additional oscillatory motions that are not encountered in loaded EHL contacts, but in loose gears, particularly at higher bulk oil temperatures and increased wheel-supporting shaft clearance. This effect is very similar to the variable compliance effect in ball and rolling element bearings with insufficient preload and interference fit, where the emergence of loaded and unloaded zones causes vibrations that are regarded as inherent (see Rahnejat and Gohar [28] and Wardle and Poon [29]). The values obtained for $\partial W / \partial h$ are far lower than those in EHL contacts, being at least 1-2 orders magnitudes higher (particularly note the reduced hydrodynamic contact stiffness at the higher bulk oil temperature in Fig. 7(e)). This suggests that a cure for rattle can only be sought by promoting conditions that pertain to EHL in loose gears. This means increasing the drag torque in the loose wheels-shaft conjunctions.

Finally, De la Cruz et al. [27] describe results acquired under the same creep rattle conditions as those simulated here, using a vehicle resisted by a rolling road dynamometer. Figure 8 shows the spectrum of vibrations for the second output shaft, obtained by an accelerometer positioned on the bearing housing. The spectrum shows a number of frequencies, comprising meshing frequencies and their harmonics, as well as engine order vibration.

Table 4 presents the meshing frequencies of each gear and their harmonics. These are noted in Fig. 8. Of particular interest is the prominent contribution of

Table 4 Corresponding meshing frequencies for all gear sets

\begin{tabular}{llll}
\hline $\begin{array}{l}\text { Gear } \\
\text { pair }\end{array}$ & $\begin{array}{l}\text { Meshing } \\
\text { frequency, } \\
\Omega(\mathrm{Hz})\end{array}$ & $\begin{array}{l}\text { Second } \\
\text { harmonic, } \\
2 \Omega(\mathrm{Hz})\end{array}$ & $\begin{array}{l}\text { Third } \\
\text { harmonic, } \\
3 \Omega(\mathrm{Hz})\end{array}$ \\
\hline First & 174 & 348 & 522 \\
Second & 290 & 580 & 870 \\
Third & 385 & 770 & 1155 \\
Fourth & 464 & 928 & 1392 \\
Fifth & 505 & 1010 & 1515 \\
Sixth & 464 & 928 & 1392 \\
Reverse & 107 & 214 & 321 \\
\hline
\end{tabular}


the second gear $2 \Omega_{2}$, which is due to the engaged pair and is also evident in the spectrum of vibration of the predicted impact force in Fig. 7(a). The experimental spectrum also contains contributions noted in the predicted fifth loose gear vibration (see Fig. 6(d)). Aside from providing a degree of credence to the numerical predictions, the existence of spectral contributions due to impact forces indicates a clear transmission path for the rattle phenomenon: from impact sites, along the transmission shafts and through the bearings to the bell housing and the environment beyond. The lower spectral contributions in Fig. 8 are engine order harmonics (dominance of $2 \omega$ and $4 \omega$ is because of the four-stroke, four-cylinder engine).

\section{CONCLUSIONS}

The article has presented a fairly detailed transmission model, comprising key interactive physical phenomena, such as inertial dynamics, contact mechanics/tribology, and thermal effects; these may be termed as multi-physics. These phenomena span a range of physical scales from sub-micrometer lubricant film thickness to large rotational displacement dynamics of shafts and gears; thus a problem spanning a range of physical scale. Such detailed analyses enable the study of the underlying reasons for the phenomena, in this case transmission rattle. It is shown that engine order vibration, resident on the transmission input shaft, excites torsional vibration of loose wheels on the lay shafts. The reason for this has been a trend towards high-torque diesel engines and size reduction of transmission systems. Various palliatives have been used, such as DMF or clutch predampers, all at significant costs in mass manufacture, with partial success and with some unintended side effects.

Root-cause solution is seen in the use of lubricant as an attenuation source. However, its behaviour in various conjunctions, all in a state of transient, is not understood. This article sheds some light on the complexity of issues, and does provide a good understanding of the mechanisms underlying the contributions of various lightly and heavily loaded lubricated conjunctions in attenuation or inducement of rattle.

\section{ACKNOWLEDGEMENTS}

The authors would like to thank Ford Motor Company (University Research Programme scheme) and the Engineering and Physical Sciences Research Council (EPSRC) for the financial support extended to this project.

(C) Authors 2010

\section{REFERENCES}

1 Rahnejat, H. Multi-body dynamics: vehicles, machines and mechanisms, 1998 (Professional Engineering Publications (IMechE), Bury St Edmunds and SAE, Warrendale, Pennsylvania, USA)

2 Foellinger, H. Advanced CAE simulations and prediction of drivetrain attributes. In Multi body dynamics: monitoring \& simulation techniques III (Eds H. Rahnejat and S. J. Rothberg), 2004 (Professional Engineering Publishing, UK).

3 Wang, M. Y. and Zhao, R. M. W. Gear rattle modelling and analysis for automotive manual transmissions. Proc. IMechE, Part D: J. Automobile Engineering, 2001, 215, 241-258.

4 Brancati, R., Rocca, E., and Russo, R. A gear rattle model accounting for oil squeeze between the meshing gear teeth. Proc. IMechE, Part D: J. Automobile Engineering, 2005, 219, 1075-1083. DOI: 10.1243/09544075X34757.

5 Theodossiades, S., Tangasawi, O., and Rahnejat, H. Gear teeth impacts in hydrodynamic conjunctions promoting idle gear rattle. J. Sound Vibr., 2007, 303, 632-658.

6 Gnanakumarr, M., Theodossiades, S., and Rahnejat, $\mathbf{H}$. The tribo-contact dynamics phenomenon in torsional impacts of loose gears-promoting gear rattle. In Proceedings of the Society of Automotive Engineers (SAE)-ATT Congress, Paris, 2002, SAE paper 02-ATT-138.

7 Mehdigoli, H., Rahnejat, H., and Gohar, R. Vibration response of wavy surfaced disc in elasohydrodynamic rolling contact. Wear, 1990, 139, 1-15.

8 Seaman, R., Johnson, C., and Hamilton, R. Component inertial effects on transmission design. SAE paper 841686, 1985.

9 Bellomo, P., De Vitto, N., Lang, C.-H., and Scamardi, L. In depth study of vehicle powertrains to identify causes of loose components rattle in transmissions. SAE paper 2002-01-0702, 2002.

10 Kizuka, T. and Fujimoto, T. Audible noise simulation. In Proceedings of the SAE 2003 World Congress, Detroit, Michigan, 2003, SAE paper 2003-01-0674.

11 Dogan, S. N., Ryborz, J., and Bertsche, B. Design of low noise manual automotive transmission. Proc. IMechE, Part K: J. Multi-body Dynamics, 2006, 220, 79-95. DOI: 10.1243/14644193JMBD10.

12 Steinel, K. and Tebbe, G. New torsional damper concept to reduce idle rattle in truck transmissions. SAE paper 2004-01-2722, 2004.

13 Gohar, R. and Rahnejat, H. Fundamentals of tribology, 2008 (Imperial College Press, London).

14 Rahnejat, $\mathbf{H}$. Computational modelling of problems in contact dynamics. Eng. Anal. Comput. Mech., 1985, 2(4), 192-197.

15 Gohar, R. Elastohydrodynamics, 2001 (Imperial College Press, London).

16 Grubin, A. N. Contact stresses in toothed gears and worm gears. Book 30 CSRI for technology and mechanical engineering, Moscow (1949) DSRI Trans., no. 337.

17 Dareing, D. W. and Johnson, K. L. Fluid film damping of rolling contact vibrations. Proc. IMechE, J. Mechanical Engineering Science, 1975, 17, 214-218. DOI: 10.1243/ JMES_JOUR_1975_017_031_02.

18 Teodorescu, M., Votsios, V., Rahnejat, H., and Taraza, D. Jounce and impact in cam-tappet conjunction induced 
by the elastodynamics of valve train system. Meccanica, 2006, 41, 157-171.

19 Johson, K. L. and Tevaarwerk, J. L. Shear behaviour of EHD films. Proc. R. Soc. Lond. Ser. A, 1975, 356, 215-236.

20 Greenwood, J. and Tripp, J. The contact of two nominally flat rough surfaces. Proc. Instn Mech. Engrs, 1970-1971, 185, 625-633. DOI: 10.1243/PIME_PROC_1970_185 069_02.

21 Teodorescu, M., Balakrishnan, S., and Rahnejat, H. Integrated tribological analysis within a multi-physics approach to system dynamics. In Proceedings of the Life Cycle Tribology, 31st Leeds-Lyon Tribology Symposium, Leeds, UK, 2005.

22 Stribeck, R. Die Wesentliechen ichen Eigenschaften Gleit un Rollen Lager (Ball bearings for various loads). Trans. ASME, 1907, 29, 420-463.

23 Teodorescu, M., Taraza, D., Henein, N. A., and Bryzik, W. Simplified elasto-hydrodynamic friction model of the cam tappet contact. In Proceedings of the SAE World Congress and Exhibition, Detroit, Michigan, USA, March 2003, SAE paper 2003-01-0985.

24 Fujimoto, T. and Kizuka, T. An improvement of the prediction method of idling rattle in manual transmission. SAE paper 2001-01-1164, 2001.

25 Cameron, A. The principles of lubrication, 1966 (Longmans, London).

26 Houpert, L. New results of traction force calculations in elastohydrodynamic contacts. Trans. ASME, J. Tribol., 1985, 107, 241-248.

27 De la Cruz, M., Theodossiades, S., Rahnejat, H., and Kelly, P. Numerical and experimental analysis of manual transmissions - gear rattle. SAE paper 2009-01-0328, 2009.

28 Rahnejat, H. and Gohar, R. The vibrations of radial ball bearings. Proc. IMechE, Part C: J. Mechanical Engineering Science, 1985, 199, 181-193. DOI: 10.1243/PIME_ PROC_1985_199_113_02.

29 Wardle, F. P. and Poon, S. Y. Rolling bearing noise - cause and cure. Chart. Mech. Engrs., 1983, 30, 36-40.

\section{APPENDIX}

\section{Notation}

$a$

$A_{\mathrm{a}}$

$A_{\mathrm{e}}$

$b$

$c$

cc

$C_{\mathrm{p}}$

E

$E^{*}$

$F_{i, j}$

$F_{p i}$

$G_{\mathrm{e}}$

$G_{\mathrm{V}}$

$h$

$h_{\mathrm{o}}$

major semi-half-width of the contact

elastostatic Hertzian contact area

asperity contact area

minor semi-half-width of contact

clearance between the loose wheel and the retaining shaft

centre distance

specific heat capacity

modulus of elasticity

effective elastic modulus

flank friction per teeth pair

Petrov friction of loose wheel

elastic Greenwood parameter

viscosity Greenwood parameter

film thickness

film thickness at the elasto-hydrodynamic conjunction
$I_{\text {os }}$

$I_{\mathrm{PR}}$

$I_{2}$

$k_{\mathrm{t}}$

$l$

$l_{\mathrm{brg}}$

$l_{\mathrm{p}}$

$m$

$N$

$p$

$p_{\mathrm{m}}$

$Q_{\mathrm{s}}$

$r_{\mathrm{p}}$

$r_{\mathrm{pp}}$

$r_{\mathrm{pw}}$

$r_{\mathrm{w}}$

$r_{x i, j}$

$r_{y}$

$R_{\mathrm{bp}}$

$R_{\text {brgi }}$

$R_{\mathrm{bw} i}$

$R_{\mathrm{ow}}$

$R_{\mathrm{p}}$

$R_{\mathrm{w}}$

$T_{\mathrm{D} 2}$

$u$

$\Delta u$

$u_{\mathrm{brg}}$

inertia of loose wheel

inertia of output shaft

inertia of reverse pinion

inertia of second gear

thermal conductivity of lubricant

contact length

gear blank width

distance between the instantaneous

contact point and the pitch point,

measured along the contact path

equivalent mass

relative rotation of the loose wheel and the retaining shaft in $\mathrm{rev} / \mathrm{s}$

pressure

mean pressure in the loaded conjunction side leakage flow

principal radius of the pinion in the $x-z$ plane

principal radius of the pinion at the pitch point in the $x-z$ plane

principal radius of the wheel at the pitch point in the $x-z$ plane

principal radius of the wheel in the $x-z$ plane

equivalent radius of the teeth pair in the

$x-z$ plane

equivalent radius in the $y-z$ plane

base radius of the pinion

radius of the supporting shaft of the

loose wheel

base radius of the wheel

outer radius of the wheel

principal radius of the pinion in the $y-z$

plane

principal radius of the wheel in the $y-z$

plane

resistive torque of differential referred to second gear

speed of entraining motion

sliding velocity

speed of entraining motion in the loose wheel-to-shaft conjunction

$v_{\text {pitch,p pitch velocity of the pinion }}$

$\nu_{\text {pitch,w }} \quad$ pitch velocity of the wheel

$W_{\text {brg }} \quad$ hydrodynamic load in the loose

wheel-to-shaft conjunction

$W_{\mathrm{e}} \quad$ load carried by asperities

$W_{i, k} \quad$ contact load per teeth pair

$x^{\prime} \quad$ direction of entraining motion

$z^{\prime}$

$\alpha$

$\alpha_{\mathrm{n}}$

$\alpha_{\mathrm{t}}$

$\beta$

$\beta_{\mathrm{o}}$

$\delta$

direction through the oil film thickness

pressure-viscosity coefficient

normal pressure angle

transverse pressure angle

helix angle

viscosity-temperature coefficient

elastic deflection

eccentricity ratio 


\begin{tabular}{|c|c|c|c|}
\hline $\begin{array}{l}\zeta \kappa \sigma \\
\eta\end{array}$ & $\begin{array}{l}\text { roughness parameter } \\
\text { effective dynamic viscosity }\end{array}$ & $\sigma$ & $\begin{array}{l}\text { root mean square roughness of } \\
\text { counterface surfaces }\end{array}$ \\
\hline$\eta_{\mathrm{o}}$ & effective dynamic viscosity at bulk oil & $\tau$ & shear stress \\
\hline & temperature and atmospheric pressure & $\tau_{\mathrm{o}}$ & Eyring shear stress \\
\hline$\theta$ & temperature & $v$ & Poisson's ratio \\
\hline$\theta_{\text {inlet }}$ & bulk oil temperature & $\varphi_{i}$ & rotational displacement of wheel \\
\hline$\theta_{\mathrm{o}}$ & lubricant temperature in contact & $\varphi_{\mathrm{os}}$ & rotational displacement of output \\
\hline$\kappa$ & asperity tip radius & & shaft \\
\hline$\lambda$ & Stribeck oil film parameter & $\varphi_{\mathrm{p}}$ & rotational displacement of the \\
\hline$\rho$ & density & & pinion \\
\hline$\rho_{\mathrm{p}}$ & radius of curvature of the pinion & $\psi$ & attitude angle in the wheel-to-shaft \\
\hline$\rho_{\mathrm{W}}$ & radius of curvature of wheel & & conjunction \\
\hline
\end{tabular}

